\title{
Improve Outcomes in Lean Six Sigma with Servant Leadership
}

\author{
David W. Hoffa, PhD, CSSBB, CSTM, CMfgT \\ Johnson \& Johnson \\ dhoffa@its.jnj.com
}

\author{
Chad Laux, PhD, CSSBB, CSTM \\ Purdue University \\ claux@purdue.edu
}

Manal Alduraibi

Purdue University

maldurai@purdue.edu

\begin{abstract}
Purpose: The purpose of this study was to explore leadership within Lean Six Sigma (LSS). The objective of this paper was to explore how LSS program success might be improved by focusing Black Belt efforts on mentoring Green Belts with a proposed servant leadership model. The effects of prioritizing of Green Belt development and building an improvement culture over the traditional Black Belt project focus is explored.

Design/Methodology/Approach: The methodology of this paper is inspired by the authors' field experiences in managing LSS strategies and due to the limited literature, is descriptive, rather than empirical. This study includes a review of relevant journal articles and a synthesis of findings based upon an operations management theory-building approach for proposing a LSS servant leadership model.
\end{abstract}

Findings: We propose a Servant Leadership Model for LSS which includes: building trust, prioritizing Green Belt development ahead of personal project goals, prioritizing culture building over project results, Black Belt focus on managing Green Belts, and the inclusion of non-financial projects.

Research Limitations/Implications: This study is limited to the theoretical nature of the work, where the methods are limited to the specific research concepts, lacking external validity.

Value: The value of this paper is a proposed model for servant leadership in LSS, which has been observed to produce superior results. This approach may be of interest to LSS researchers and practitioners at all levels.

Research Keywords: Lean, Human Development, Six Sigma, Green Belt, Leadership

Paper Type: Research Paper 


\section{$8^{\text {th }}$ INTERNATIONAL CONFERENCE ON LEAN SIX SIGMA}

\section{Introduction}

Lean Six Sigma (LSS) programs often focus on the skills and abilities of their primary practitioners - Black Belts (BBs) - to discover, charter, staff, execute, and document improvement projects, and these projects are often larger opportunities which take six to twelve months to complete and which create substantial improvements (financial or otherwise). While significant and even major changes can and do result from this typical approach, the authors have discovered a potentially more impactful approach to deploying LSS; one which shifts away from the typical BB project focus, toward one which focuses BB efforts on growing and developing a corps of Green Belts (GBs) using a servant leadership model.

Based on years of LSS practitioner and leadership experience, the authors propose the fivepoint servant leadership model for improved outcomes in LSS below and in Figure 1:

1. Build trust

2. Prioritize GB development ahead of personal project goals

3. Prioritize culture building over project results

4. BB focus on managing GBs

5. Include non-financial projects

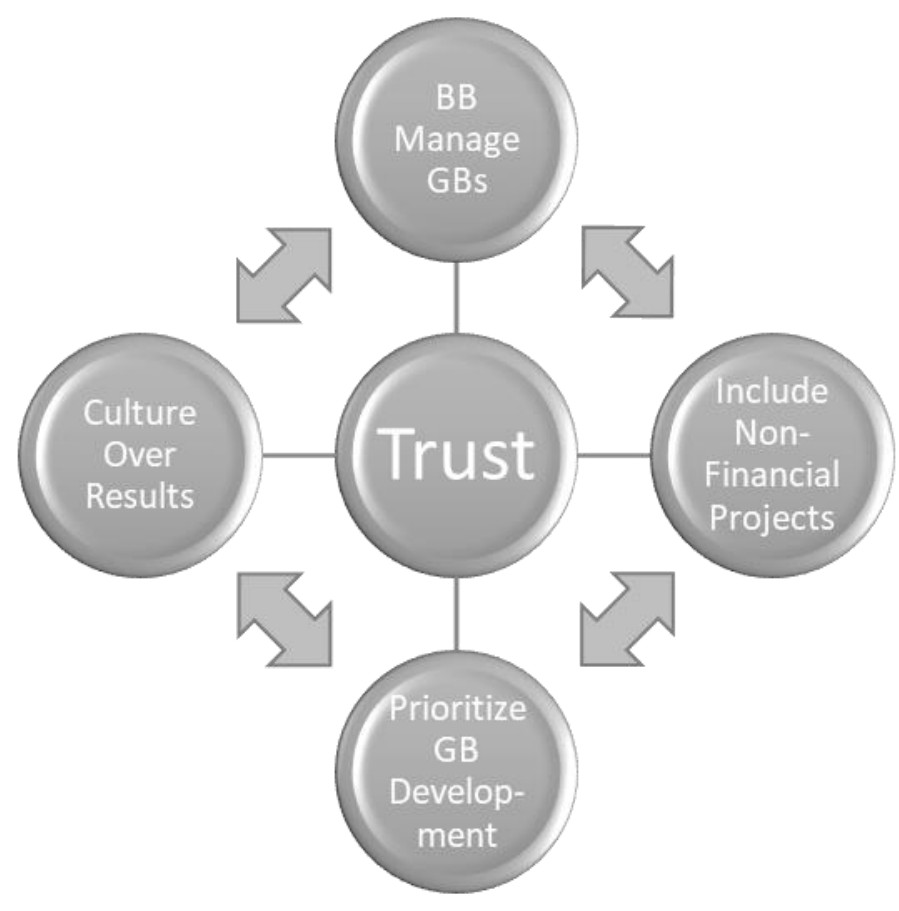

Figure 1. The Servant Leadership Model for Improved Outcomes in Lean Six Sigma.

Trust is the key enabler of the other four elements. While the five elements are interconnected, without trust as the hub, the model does not work. This paper proposes the model for additional exploration, discusses each point in detail, and answers the research question descriptively: what is a trust-based model for Lean Six Sigma? 


\section{Methods}

A literature review of the main domains was conducted, to review articles that present the current knowledge about the related topics in this paper. "The literature review is an attempt to summarize the existing state of knowledge about a subject and, in research proposals, to frame the proposed research's expected contribution to knowledge" (Knopf, 2006, p.128). This literature review includes reviews of papers on servant leadership, trust, organizational culture, and non-financial projects.

In this paper, we took a research approach posited by Meredith's (1993) theory building in operations management through an iteration of discussion and reflection between the Lead Author (interviewee) and Secondary Authors' (interviewer) discussions of prior work experience, and evidence, to understand the role of trust in the Lean Six Sigma approach. The authors discussed and reflected upon experiences as subject matter experts, the issue of trust in conducting LSS projects. Specifically, we adopted a qualitative interviewing approach, where the interviewer generates talk with an interviewee for the purpose of eliciting spoken data by which to examine the research problem (Roulston, 2010). Interviews were conducted via virtual means, both by phone and video, at one-hour intervals, for an estimated total time of 10 hours of dialogue. The interviews were semi-structured and based upon question-andanswer sequences, where open ended questions were asked, reflected upon by the interviewee, and sometimes the interviewer, to serve as probes and facilitation through dialogic interviewing (Roulston, 2010).

The starting point for these discussions was Hinds' (2019) model, which was the lead author's primary prompt for this research. The specific observations for dialogue was subject matter expertise in managing LSS projects, personnel involved in those projects, primarily GBs, and project success. The dialogues moved between these specific observations to broader generalizations, where the reasoning was inductive, and in line with Meredith's (1993) model building approach.

When the Lead Author found himself in a challenging position - placed as a full-time Lean Six Sigma Black Belt at a newly-acquired worksite at which trust was low and resistance to change was high - he also found himself determined to succeed and deliver on an aggressive slate of annual goals, so he developed the servant leadership model proposed in this paper on the fly. Only after having gone through this dialogic interviewing process did the five key activities employed during that time, and their corresponding model, come into clarity.

\section{Literature Review}

Servant leadership tends to help and serve others, promotes a sense of community, and shares the decision making (Center, 1991). "The Servant-Leader is a servant first... ...it begins with the natural feeling that one wants to serve, to serve first. Then conscious choice brings one to aspire to lead" (Greenleaf, 2002). In LSS, servant leadership may take many forms, but the lead authors' experiences and observations have informed the presented model, which if it were further condensed, could be stated as BB focusing one's energies on growing and developing others for the greater good (greater business results, greater culture, greater program sustainability, etc.) instead of on their own projects. Although the literature contains little about the importance of GB-level practitioners, we will present a review of relevant literature in trust, organizational culture, and the value of non-financial projects. 
Trust

We propose that Six Sigma project performance is based upon both technical and nontechnical aspects. In a highly cited paper, Arumugam, Antony, and Kumar (2013) note that as teams learn within a project, the implementation requires technical and process approaches. LSS projects are conducted by team members that are tasked with completing objectives. This process approach is socially based upon team member interactions that leads to a basis of trust, or as Kahn (1990) states, a willingness to act and engage, rather than to retreat within. The ability of a LSS team to perform well on project tasks relies upon a safe environment to take risks, especially when the team's tasks have a measure of uncertainty, a characteristic of the discovery required for successful DMAIC projects (Arumugam, Antony, and Kumar, 2013). Team members may not do what is needed on LSS projects if trust is lacking among team members.

LSS team members activities on projects include team problem solving, comprehension, understanding problems, and generating knowledge (Choo, Linderman, and Schroeder, 2013). These tasks, through the perspective of DMAIC, often require engagement among team members to produce quality work, based upon cross-functional expertise of LSS teams. Often, these DMAIC tasks are completed through dialogue, an important aspect of socialization of team members (Nonaka and Takeuchi, 1994). If a conducive and comfortable team climate exists, characterized by interpersonal trust, then team members may feel psychologically safe to engage with other members, to conduct LSS project tasks, through seeking information, discussion, and interaction (Edmonson, 1999; Nahapiet and Ghoshal, 1998).

\section{Organizational Culture}

Organizational culture refers to a set of behaviors established within an organization. Among several scholarly definitions of the term provided by a number of authors and researchers, the one that is most commonly used was given by Lundy and Cowling (1996), who defined organizational culture as "the way we do things around here". As Smircich (1983) states: "a culture is something an organization is" and thus organizational culture can be seen as the basis of performance in an established organization. Furthermore, Siehl et al. (1981) define it as a "social or normative glue that holds an organization together". From Knapp's perspective, this "culture provides the organizational members a unifying purpose and sense of community" (Knapp, 2015, p.856).

A number of researchers and professionals believe that organizational culture is in fact developed by the values, norms, and beliefs that people hold and share within an organization (Brown, A. 1995, 1998; Cooke and Lafferty, 1989; Elqadri, 2015; Martins, and Martins, 2003; Ogbonna, 1992; Sun, 2009). Organizational culture affects the ways organizations do things; therefore, it can be considered as one of the factors that may impact a firm's strategy, management processes, and consequently, the outcomes of projects, since it determines how they were managed and executed in the first place. A plethora of existing literature shows the significant role that culture has on organizations' performance, individual satisfaction, outcome of projects, problems solving, and so on (Waterman and Peters, 1982; Zu, Robbins and Fredendall, 2010). 
Organizations need to take their culture into account. Managers should be aware of the cultural values emphasized in their own organization so that the multiple LSS practices may be effectively concluded ( $\mathrm{Zu}$ et al., 2010).

\section{Non-Financial Projects}

Non-financial projects could strengthen employee engagement through different practices where the project benefits add value to the entire organization (Humborstad, and Perry, 2011). These projects are expected to identify benefits and competitive advantages for the organization that financial projects may not capture.

Providing room for non-financial projects could contribute to enhancing employee satisfaction through value-added behaviors such as discretionary work effort (DWE). Gonzales (2016) defines DWE as "a volunteer effort of the individual in favor of the organization that goes beyond what is minimally required" (p.199), and Entwistle (2001) said DWE is "the energy under individual's control, beyond what is minimally required by the organization, spent on behalf of the organization and for their benefit". In other words, employees need to feel free to provide extra effort just because they want to, and they can still get needed support from the organization. Correspondingly, non-financial projects could have a beneficial impact on the effectiveness of an organization since the employee is providing extra work that exceeds what is required and expected by the organization (Morris, 2009).

\section{Discussion}

\section{Trust}

Trust is the hub of the model because the other four points rely upon it in order to be effective. At the outset of this improvement journey, the Lead Author realized the environment was not conducive to achieving results. "We don't need any LSS here" and "this isn't Toyota - that won't work here" were common manifestations, but the underlying issue was trust. After engaging in several challenging discussions in which a lack of trust was indicated, he realized trust would need to be built before any pursuit of business results could even be considered.

Trust was established over time by committing to a "mean what you say and say what you mean" relationship with each key player. Positioning himself as a coach and mentor, the Lead Author promised each GB candidate to help them complete projects and made them the center of attention when they did, linking all results to an overarching storyline of "building a better plant for Corporate". Through a simple policy of honesty, no erosion of trust was permitted to corrupt these relationships. Over time, folks at the plant learned that the Lead Author was trustworthy, and LSS really could improve things, and the other four points of the model became increasingly viable.

It was recognized early on that little was possible as a BB working alone. Even to work on one's own BB projects, the support and buy-in of a wide swath of site personnel is required, and the lack of either likely means the death of not only whatever projects are at hand, but the entire continuous improvement initiative. To remedy this, the Lead Author worked with his corps of GB trainees on a daily basis, discussing their ideas and helping them to capture them as LSS projects. These GB candidates were acknowledged and recognized within the site for 
making improvements, which was systematized in a few simple ways: by blanketing the site with one-page project closure summaries in a standard format; by sending those project summaries to key management personnel regardless of physical location, and by reporting out the results in monthly meetings with key management personnel. Posting project results around the shop brought awareness to everyone on the site and contributed to building up the improvement culture, whereas the other means contributed to creating awareness of that growing culture within the management ranks.

Along the way, there were many opportunities to make an improvement observation into a BB project, but instead, the Lead Author pulled in the most relevant GB candidate and handed the idea over to them, for their own betterment, in terms of moving closer to the certification goals, to grow and sustain individual trust, and to further enhance the growing culture of achievement and improvement. It became clear that this was an effective approach when people began asking how they, too, could get involved.

In a low trust/high resistance environment, it rapidly becomes evident that not much is going to get done without focusing on something other than business results. Project contributors only engage so far as they are ordered by their superiors, and they likely do not care if the project succeeds or fails. The Lead Author had the good fortune of closing his first BB project above the entire annual savings goal, which permitted him to shift the focus off of savings and onto culture, in terms of getting more people involved, building their trust, closing GB projects, and celebrating their successes. Whereas the first half of the first year in his role was consumed entirely by that first project, the second half was comprised of seven closed GB projects from five individual leaders, and saved a staggering 1,200\% increase in savings over that first BB project. These results were communicated far and wide as plant achievements led by GB candidates, enhancing trust between BB and GB, growing the culture of improvement, and getting more people interested in being involved as project leaders or contributors. What was eventually realized was that by taking the focus off of results and onto GB achievement, getting people involved, and building an improvement culture, the financial savings came along without even trying. This might be summarized as if you prioritize results ahead of culture, you will get neither but if you prioritize culture before results, you will get both, which gets close to Shingo's (1990) guiding principle of respect for the individual.

\section{Organizational Culture}

When organizational changes meant that a daily presence at the worksite was no longer possible, the Lead Author found that daily activity and progress could be better achieved by putting a larger focus on coaching a larger corps of GB candidates rather than trying to work on his own BB projects. In this company, BBs were expected to be leaders and executors of improvement projects, whereas GBs were very much considered "second tier" in importance. However, he realized that he could manage the needs of many GB candidates and their projects, providing spot coaching as needed, keeping forward momentum and engaging more people in not only achieving business results, but in helping people with their personal goals and building up a culture of improvement.

\section{Non-Financial Projects}

Eventually, as the corps of GBs and projects closures grew, it became clear that greater business results were possible by closing more, smaller projects as opposed to pursuing a 
time/capacity-limited number of BB projects. A simplified model of this phenomenon appears in Figure 2. The values in the model are based on Johnson and Johnson's guidance on financially scaling GB and BB projects, and it is well-acknowledged that actual project results can vary widely.

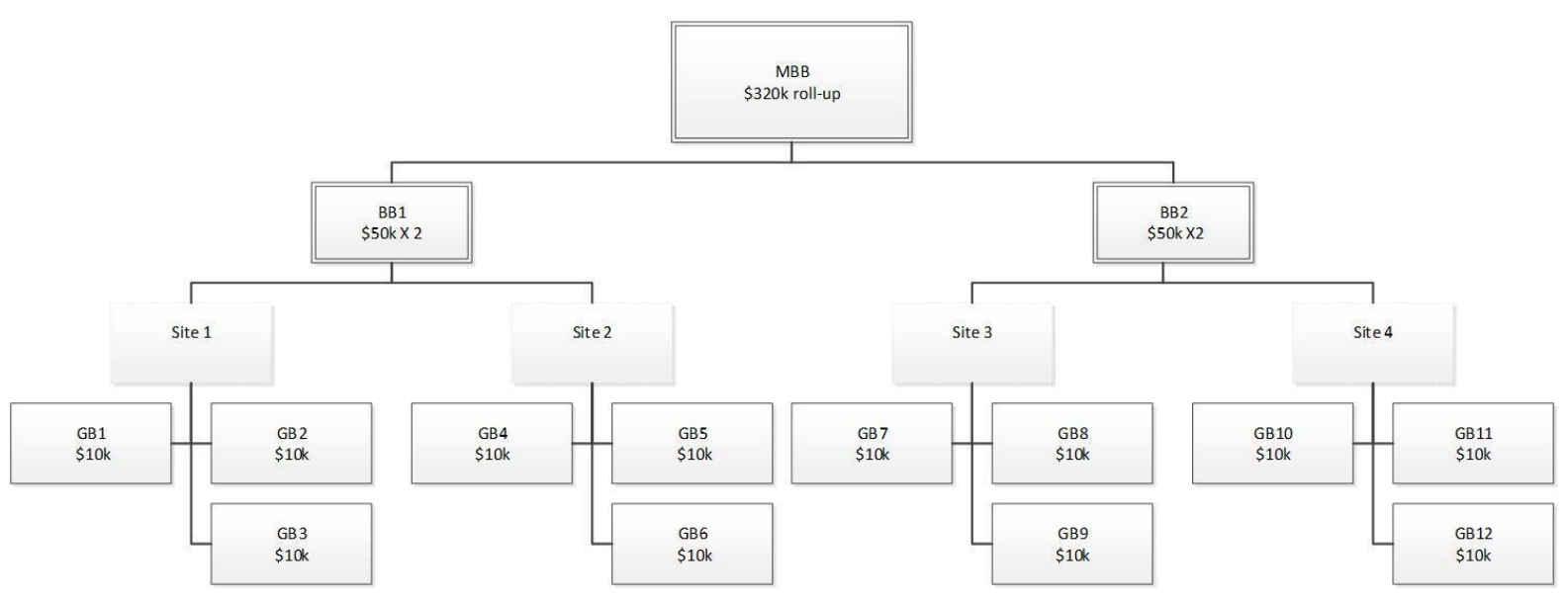

Figure 2. Organizational Business Model

How do you build a culture of improvement if only Operations staff can work on projects? How can you get the whole staff involved if only shop floor savings projects are viable? How can you build trust if only a portion of the staff have a seat at the table? While these are certainly possible without non-financial projects, it is the experience of the authors that opening the improvement conversation to everyone makes it much easier and effective. Using

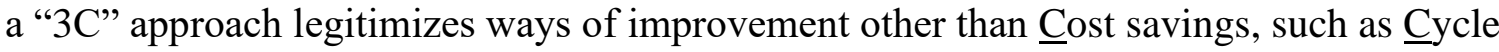
Time Reduction or Customer Satisfaction Improvement. When these are seen not only as legitimate but actually encouraged, people from departments and functions outside of Operations can see how the work they do can be improved. For example, a Safety Engineer can now use LSS to eliminate safety risks; the HR manager can pursue an improvement in customer satisfaction in the hiring process; the site accountant can pursue a Cycle Time Improvement in the monthly close process. Casting the widest possible net makes it possible to get more people involved, which supports the culture building and ultimately, yields greater results.

\section{Results}

How did the application of these five points affect performance? An analysis of 11 yearsworth of data (over 1,700 closed projects) from that same company's Lean Six Sigma program found that BBs closed, on average, 2.9 BB-owned projects per year, and 6.3 "coached" projects (any project led by someone other than the BB, including GB projects) per BB per year. Using the model, the Lead Author achieved noticeably (not statistically) different results (averaged from two years, rough rounding applied). Whereas performance in BB project closure count was below average at just two, coached project closures were higher (12), resulting in a total of 14 closed projects, or a $66 \%$ increase in project closures over the average $\mathrm{BB}$, whose pooled average (BB and coached projects together) was 8.4.

The Lead Author applied the model at another company, as well as could be done in an environment that did not support it. There, visitors to the site began noticing the uniqueness 
of the site's culture, where they regularly reported observing the hourly staff leading lean conversations, trying to convince their peers or even their superiors to undertake improvement activities and remove waste from processes. In a period of three years, and without proper support, this site became the leader in Lean certifications, certifying more than a dozen Yellow and Green Belts.

With only a little modification, the model applies equally-well at the MBB level. As an MBB, the Lead Author continued applying the model with the recognition that many BBs were having similar struggles to those he experienced as a BB. By having the BBs apply the model to their work and applying the model himself at the MBB level, divisional results began to grow.

\section{Conclusions}

The servant leadership model presented in this paper was developed out of the need to find a path to success for Black Belts in a challenging environment. While each point of the model was developed and applied in real time, it was only years after the fact, after reminiscing, recall, and post hoc reflection of those years with colleagues, utilizing interviews, that the model was formed as presented herein. As a result, the model has not been empirically tested - only experientially so - leaving ample opportunity for additional research. Regardless, the observed benefits of this model include increased results, both in terms of savings and closures, and a cultural shift toward one that is improvement- and achievement-oriented.

\section{References}

Arumugam, V., Antony, J., \& Kumar, M. 2013. Linking learning and knowledge creation to project success in Six Sigma projects: An empirical investigation. International Journal of Production Economics. 141(1), pp. 388-402.

Brown, A., 1995, 1998. Organizational Culture, 2nd edn, Pitman Publishing, London.

Center, R.K.G., 1991. Servant-leadership resources available from the Robert K. Greenleaf Center. Indianapolis, IN: The Robert K. Greenleaf Center

Choo, A.S., Linderman, K., Schroeder, R.G., 2007. Method and psychological effects on learning behaviors and knowledge creation in quality improvement projects. Management Science. 53(3), pp. 437-450.

Cooke, R.A. and Lafferty, J.C., 1989. Organizational culture inventory. Plymouth, MI: Human Synergistics.

Edmondson, A.C., 1999. Psychological safety and learning behaviour in work teams. Administrative Science Quarterly. 44(2), pp. 350-383.

Elqadri, Z.M., 2015. The influence of organizational culture, organizational climate, and the promotion of the position of employee job satisfaction in PT. Surabaya Graphics Media Temprina. Asian Social Science, 11(22), p.139.

Entwistle 3rd, G.H., 2001. Measuring effort expended in the workplace: Discretionary effort and its relationship to established organizational commitment and attachment dimensions. Boston University.

Gonzales, A.R., 2016. Discretionary Work Effort and Organizational Citizenship Behavior: Investigating Brazilian Teachers' and Public Officials' Behavior. Global Advance Research Journal Management Business Studies, 5(8), pp.198-204. 


\section{$8^{\text {th }}$ INTERNATIONAL CONFERENCE ON LEAN SIX SIGMA}

Greenleaf, R.K., 2002. Servant leadership: A journey into the nature of legitimate power and greatness. Paulist Press.

Hinds, D., 2019. Why Trust is So Important and How to Build It with Lean Management. ASQ LED.

Humborstad, S.I.W. and Perry, C., 2011. Employee empowerment, job satisfaction and organizational commitment. Chinese Management Studies.

Kahn, W.A., 1990. Psychological conditions of personal engagement and disengagement at work. Academy of Management Journal. 33(4), pp, 692-724.

Knapp, S., 2015. Lean Six Sigma implementation and organizational culture. International journal of health care quality assurance.

Knopf, J.W., 2006. Doing a literature review. PS: Political Science and Politics, 39(1), pp.127-132.

Lundy, O. and Cowling, A., 1996. Strategic Human Resource Management. London: International Thompson Business Press.

Martins, N. and Martins, E., 2003. Organisational culture. Organisational behaviour: Global and southern African perspectives, 379, p.400.

Meredith, J., 1993. Theory building through conceptual methods. International Journal of Operations \& Production Management.

Morris, R.J., 2009. Employee work motivation and discretionary work effort (Doctoral dissertation, Queensland University of Technology).

Nahapiet, J., Ghoshal, S., 1998. Social capital, intellectual capital, and the organizational advantage. Academy of Management Review. 23(2). Pp. 242-266.

Nonaka, I., Takeuchi, H., 1995. The Knowledge-Creating Company: How Japanese Companies Create the Dynamics of Innovation. Oxford University Press, NY.

Ogbonna, E., 1992. Managing organisational culture: fantasy or reality?. Human Resource Management Journal, 3(2), pp.42-54.

Roulston, K., 2010. Asking questions and individual interviews. Reflective interviewing: A guide to theory and practice, pp.9-33.

Siehl, Caren, and Joanne Martin., 1981, 'Learning organizational culture', Unpublished manuscript, Graduate School of Business, Stanford University.

Shingo, S.,1990. Modern approaches to manufacturing. Productivity Press.

Smircich, L., 1983. Concepts of culture and organizational analysis. Administrative science quarterly, pp.339-358.

Sun, S., 2008. Organizational culture and its themes. International Journal of Business and Management, 3(12), pp.137-141.

Waterman, R.H. and Peters, T.J., 1982. In search of excellence: Lessons from America's bestrun companies. New York: Harper \& Row.

Zu, X., Robbins, T.L. and Fredendall, L.D., 2010. Mapping the critical links between organizational culture and TQM/Six Sigma practices. International journal of production economics, 123(1), pp.86-106. 